\title{
El modelo de desarrollo actual, el despojo en los territorios de los pueblos originarios y la migración
}

\section{Current development model, dispossession in the territories of the native peoples and migration}

Elizabeth Ibarra

Estimados:

Posiblemente nada de lo que diré a continuación es desconocido para muchos de los presentes, salvo que ésta es la mirada y la voz de quienes en raras oportunidades tenemos la palabra para negar o reafirmar lo que se dispone y acuerda en nuestro nombre.

\section{Una mirada comunitaria del desarrollo y la migración}

Nuestra voz, es la voz de la región de América del Centro, Mesoamérica, específicamente la región transfronteriza México-Guatemala, la cual se caracteriza por su gran biodiversidad y riqueza biológica, mineral, energética y sociocultural, que contrasta con la creciente pobreza de sus habitantes y poblaciones que viven en su mayoría del cultivo de maíz y frijol. La división política entre México y Centroamérica, a diferencia de otras zonas fronterizas, tiene especial significado: es un territorio donde 10 millones 140 mil 651 habitantes de los municipios a ambos lados de la frontera, en su mayoría mayas, con similares condiciones de vida, de cultura, y cuyos procesos comerciales, políticos y culturales los vinculan diariamente. Desde antes de la primera invasión, mantienen sus relaciones no reguladas, porque son sociales e históricas; en ellas, participan migrantes 
centroamericanos, ya sea al cruzar día a día la frontera o haciéndolo por temporadas de varios meses para laborar en las fincas (Paz, Cerda y Ledón, 2016:20).

A partir del año 1500 y durante los siglos de colonización se crearon estructuras políticas, sociales y jurídicas para el saqueo de los bienes naturales y el despojo territorial, lo que genera condiciones de precariedad en las poblaciones locales de la región transfronteriza. El diario sobrevivir de las comunidades, excluidas del paradigma de desarrollo occidental, está siendo vulnerado aún más, por las actividades extractivistas de la matriz neoliberal que son producto de acuerdos internacionales, como el Tratado de Libre Comercio de América del Norte (TLCAN) y el Acuerdo de Asociación Transpacífico (ATP), los cuales profundizan la explotación de recursos naturales con el discurso de una inserción competitiva en el mercado regional liberalizado. Es así como dicho modelo aterriza en los territorios transfronterizos con planes y programas de desarrollo regional impuestos por los organismos financieros internacionales y ejecutados por los gobiernos nacionales: la Estrategia de Desarrollo Regional del Mundo Maya-Frontera Sur, el Programa Integral de la Frontera Sur y las Zonas Económicas Especiales, ejecutados en México; el Plan Alianza para la Prosperidad, que tiene lugar en Guatemala, Honduras y El Salvador; y el Proyecto de Integración y Desarrollo de Mesoamérica.

En 2014 y posterior a la migración alarmante niños no acompañados hacia Estados Unidos, se puso en marcha la aplicación de una «Alianza para la Prosperidad» que incluye a los tres principales expulsores de migrantes de Centroamérica. El plan, financiado en gran medida con fondos de deuda externa por cada uno de los países supuestamente «beneficiados», resulta ser un atractivo negocio para las elites empresariales que ven una nueva oportunidad para incrementar sus capitales. Cabe mencionar que ha sido fundamentado y dirigido por las oligarquías locales, a la vez que busca respaldar el saqueo a gran escala de lo poco que han dejado en las comunidades indígenas. A dos años de su implementación, puede afirmarse que el plan no ha atendido las causas estructurales que motivan a numerosas personas a dejar su comunidad; al contrario, ha efectuado grandes dispositivos fronterizos, que incrementaron nuevas y más peligrosas rutas de tránsito ilegal.

El paradigma de «desarrollo» actual desprecia la vida y la salud de las comunidades, para dar preferencia a las ganancias del capital transnacional, el cual no tiene límites en su avaricia y está provocando destrucción, muerte, 
desesperanza y expulsión de familias y comunidades enteras de sus territorios. La Madre Tierra, que es lo que atesoramos en las comunidades originarias, nuestra única fuente de vida y protección, es ahora el botín en disputa de los nuevos $y$ viejos invasores. La actividad extractiva somete a las comunidades rurales, en particular a los pueblos originarios, a un despojo mucho más agresivo que el de la primera invasión en 1500. Los dueños de las empresas transnacionales, en contubernio con capitalistas nacionales, operan en la cooptación de los Estados, al debilitarlos y corromper sus estructuras, hasta hacerles perder su autonomía, para saquear los recursos naturales sin responsabilidad alguna.

Despojar a los pueblos de sus territorios por la fuerza provoca la precarización de la vida de las comunidades campesinas e indígenas y genera un fuerte conflicto por la supervivencia de su ser, de su cultura, de su forma de vida, de su idioma, lo que a su vez causa en muchos casos la migración. Los desplazamientos forzados representan movimientos en busca de protección frente a la inseguridad, o de dignidad frente a la miseria y la desaparición de los modos de vida propios de cada comunidad (Celis y Aierdi, 2015).

La migración es y ha sido, desde los tiempos antiguos, la actividad humana que le dio el perfil a la civilización actual, ha sido también asociada al desarrollo de países y regiones, pero sobre todo en la actualidad es la consecuencia de actividades económicas y militares enmarcadas dentro de un sistema de producción y consumo que no se hace cargo de forma responsable, en sus costos de producción, del despojo y la contaminación que promueve. Adicionalmente, atenta contra la destrucción de nuestro hogar común y lo que hasta ahora sostiene la vida en el planeta, tal como la conocemos.

El fenómeno de la migración no puede verse alejado de lo que sucede en los territorios que expulsan a la mayoría de los migrantes. Es necesario reconocer la estrecha relación entre el modelo económico dominante y los procesos migratorios. Según la Declaración de Nueva York de la Organización de las Naciones Unidas, «el número de migrantes crece a un ritmo más rápido que el de la población mundial, en 2015 ascendió a 244 millones. No obstante, hay aproximadamente 65 millones de personas desplazadas por la fuerza, entre ellas más de 21 millones de refugiados, 3 millones solicitantes de asilo y más de 40 millones de desplazados internos» (Organización de las Naciones Unidas, 2016).

Con anterioridad ha sido documentado que la industria extractiva, el despojo de los recursos naturales en los pueblos originarios, la criminalización de los defensores en sus territorios y la falta de oportunidades para personas 
de todos los géneros, se han incrementado en los últimos tiempos, así como la necesidad de moverse para encontrar nuevas rutas de desarrollo, trabajo y paz. La pobre inversión en nuestros países en salud, educación, empleos dignos, aumenta día con día las brechas de desigualdad y eleva el capital humano que se enrola en negocios ilícitos para sobrevivir. Esos seres humanos son extorsionados, torturados, violados; son cooptados por el crimen organizado y la mayoría de ellos pierde la vida al negarse o al ser parte de las mafias que los utilizan para operar la narcoactividad, la trata de personas y el contrabando de mercancías ilícitas.

Mientras estamos aquí reunidos, miles de niños, niñas, hombres y mujeres de todas las edades, cruzan territorios peligrosos en búsqueda de oportunidades: pueden ser económicas, de estudio, o simplemente para defender la vida frente a la violencia y las guerras que, dicho sea de paso, no son «nuestras guerras", sino las guerras de la industria armamentista y de la disputa de materias primas en los territorios, que les son indispensables a los países desarrollados a fin de mantener su forma de vida y producción. Si tan sólo una tercera parte de lo que se invierte en la industria armamentista se utilizara en crear fuentes de empleo, en educación, salud y recreación de las comunidades excluidas, tendríamos mejores alternativas de desarrollo en nuestros países y la necesidad de migrar se reduciría de modo considerable. Las causas que impulsan a millones de seres humanos a migrar son prevenibles si los gobiernos a cargo hicieran su trabajo, si los legisladores jugosamente pagados con nuestros impuestos en todos los congresos y las cámaras hicieran su trabajo.

Ante la ausencia de gobernanza a cargo de los Estados en la región, los ejércitos están siendo movilizados para «proteger fronteras»; basta leer entre líneas las declaraciones recientes de la Conferencia de Seguridad de Centroamérica, donde se materializan aspectos que se gestionaron desde 2010 en la región. Bajo el argumento de combate a la narco insurgencia nuevas bases militares del Comando Sur de Estados Unidos se instalan en nuestros territorios, violando los principios básicos de nuestras constituciones nacionales: «El secretario de Defensa de Guatemala, anunció brevemente la instalación de sal menos una nueva base militar del Comando Sur de Estados Unidos en el Departamento de Petén, Guatemala»». ${ }^{1}$ El objetivo de realizar operaciones conjuntas por vías

${ }^{1}$ El Comando Sur de EUA (US South Com) es un mando conjunto integrado por militares y civiles del ejército, la armada, la fuerza aérea, los marines, la guardia costera y las agencias federales de inteligencia. Asimismo, funciona mediante operaciones especiales conjuntas, fuerzas de tareas conjuntas, una 
aérea, marítima y terrestre, a lo largo de la región transfronteriza de México con Guatemala, con el argumento de vigilar los flujos migratorios y perseguir a cárteles del crimen organizado.

Así, la consolidación de un enfoque de seguridad nacional y la militarización de los territorios queda justificada como medio para detener el terrorismo, el tráfico «ilegal» de personas, la expansión del crimen organizado y el paso de las drogas por la frontera sur de México hacia Estados Unidos. Desde ese enfoque, los pueblos organizados que reivindican y defienden derechos, las personas migrantes que ejercen el derecho de fuga y quienes defienden los territorios y los derechos humanos, son considerados como enemigos internos, mientras que se ignora la historia, la riqueza de relaciones culturales y las razones diversas de la migración en la región.

Existe una fuerte militarización de los territorios donde coincidentemente se emplazan proyectos de minería, monocultivos o petróleo; estrategia que no sólo atiende a la represión de cualquier resistencia civil, sino que incorpora fenómenos de corrupción, criminalización y creación de frentes militares especiales que a menudo actúan de la mano de grupos paramilitares, hecho que contribuye a la división del tejido comunitario (Carvajal, 2016). Por otro lado, el enfoque de seguridad, del fenómeno migratorio y el traslado de la frontera de Estados Unidos a la región transfronteriza México-Guatemala, implican una estrategia de control, detención y deportación de los flujos migratorios provenientes de Centro, Sudamérica y de otros continentes, que deshumaniza y despoja de sus derechos fundamentales a las personas migrantes y refugiadas e invisibiliza las causas de salida.

Por ello se reitera que la militarización de las fronteras terrestres ${ }^{2}$ y de los mares no es la solución, al contrario, es vulnerar aún más nuestro diario vivir, sobre todo para nosotras las mujeres; en el territorio cuerpo, al vernos acosadas por cuerpos militares de elite que agregan actividades en los territorios, con graves consecuencias para la salud: violaciones, extorsión, tráfico de armas, drogas y seres humanos, enfermedades de transmisión sexual, epidemias, contaminación

interagencia conjunta de fuerzas de tarea (Joint Interagency Task Force), y las oficinas de Asistencia para la Seguridad. Tiene su principal base de operaciones en Miami, Florida.

${ }^{2}$ «La securitización de la migración es una política migratoria impuesta por Estados Unidos a México a partir de los ataques terroristas del 11 de septiembre de 2001. Dicha política se funda en la creencia de que la migración internacional indocumentada es una amenaza para la seguridad nacional, por lo que el Estado mexicano ha desplegado prácticas y leyes específicas para detenerla» (Treviño, 2016:2). 
a gran escala de nuestros ríos y mares; es romper y corromper los tejidos comunitarios de poblaciones transfronterizas que se encuentran íntimamente unidas desde los tiempos precolombinos.

Queda así manifiesta la tensión entre los derechos humanos y lo que hoy se define como "seguridad nacional», en beneficio de un modelo comercial trasnacional, lo que demuestra que en la región transfronteriza las condiciones son aptas para que se incremente la violencia y se vulnere a sus poblaciones, en beneficio de unas cuantas minorías.

\section{A manera de conclusiones}

La expansión del sistema capitalista, en nombre del «desarrollo», está provocando estallidos sociales y conflictos que expulsan de sus comunidades a grandes flujos de población, en detrimento de las economías nacionales y en contradicción con ellas. La noción de que el desarrollo capitalista provocaría un rebalse de riqueza capaz de beneficiar a una mayor cantidad de personas ha dejado al descubierto su falacia ante la polarización de la humanidad y el engrosamiento de muy diversas clasificaciones de la pobreza.

Grandes flujos de fuerza productiva y talento en nuestras comunidades y territorios se ven forzados a migrar para la sobrevivencia en medio de la hostilidad y la xenofobia, en las que si no pierden la vida son obligadas a engrosar los cinturones de mafia y crimen organizado que de nuevo incrementan la violencia y la criminalidad.

Las comunidades indígenas y campesinas en los territorios que habitan, de los cuales son los verdaderos e indiscutibles propietarios, son una fuente de riqueza, biodiversidad y esperanza para un planeta que agotamos con el modelo de producción y consumo imperante. El deber de los Estados es proteger esta esperanza, que es además su propia fuente de vida y desarrollo.

Desde la mirada de quienes vivimos el despojo y el deterioro alarmante de los territorios indígenas, nos parece que mientras nuestros gobiernos y los gobiernos que defienden el actual modelo de «desarrollo» no reaccionen y se comprometan de manera urgente a invertir en reducir la pobreza y la falta de oportunidades, al mismo tiempo que respetan la decisión comunitaria de no concesionar sus territorios a la industria extractiva y monocultivos. En tanto no existan leyes que penalicen el contrato ilegal, mal remunerado y clandestino, 
seguiremos incrementando los índices de derechos elementales violados, frente a organismos internacionales que dicen velar por ellos.

\section{Referencias}

Carvajal, Laura María (2016), Extractivismo en América Latina: impactos sobre la vida de las mujeres y propuestas de defensa del territorio, Bogotá, Colombia, Fondo de Acción Urgente-América Latina.

Celis Sánchez, Raquel y Xavier Aierdi Urraza (2015), iMigración o desplazamiento forzado? Las causas de los movimientos de población a debate, Cuadernos Deusto de Derechos Humanos, núm. 81, Bilbao, Universidad de Deusto.

Organización de las Naciones Unidas (ONU) (2016), «Declaración de Nueva York para los Refugiados y los Migrantes», en http://www.un.org/es/comun/docs /? symbol=A/71/L.1

Paz Carrasco, Miguel Ángel, Alejandro Cerda García y Aldo Ledón Pereyra (2016), "Mirar las fronteras desde el Sur. Salud y migración en la frontera México-Centroamérica», Observatorio de Legislación y Politicas Migratorias, El Colegio de la Frontera Norte, en http://observatoriocolef.org/?articulos=mirar-las-fronteras -desde-el-sur-salud-y-migracion-en-la-frontera-mexico-centroamerica

Treviño Rangel, Javier (2016), «żDe qué hablamos cuando hablamos de la ssecuritización de la migración internacional en México?: una crítica», Foro internacional, vol. 56, núm. 2. 